\title{
RESEÑA
}

\section{MILANI, Carlos (2018). Solidariedade e Interesse: motivações e estratégias na cooperação internacional para o desenvolvimento. Ed. Appris, Curitiba}

O livro de Carlos Milani intitulado "Solidariedade e Interesse: motivações e estratégias na cooperação internacional para o desenvolvimento", publicado em $2018 \mathrm{e}$ lançado na Associação Brasileira de Relações Internacionais (ABRI) deste mesmo ano, é uma grata surpresa para os estudiosos das Relações Internacionais. Em 350 páginas, o professor da Universidade do Estado do Rio de Janeiro - Instituto de Estudos Sociais e Políticos (IESP) - compartilha suas amadurecidas reflexões e consolida sua dedicação intelectual sobre a cooperação internacional para o desenvolvimento (CID), reunindo uma série de artigos publicados anteriormente, trabalhos de pesquisa realizados e sob sua orientação. Em uma apresentação bastante didática, o livro se dirige àqueles que pretendem se iniciar nestes estudos e, também, aos pesquisadores do campo, ao indicar questões problemáticas e sugerir algumas reflexões atualizadas.

O prefácio de Letícia Pinheiro e Maria Regina Soares de Lima situam a CID como elemento constitutivo da política internacional e, portanto, um campo de estudos fundamental nas Relações Internacionais. Sobre o tema central do livro, solidariedade e interesse, as pesquisadoras ressaltam que "não somente é possível pensar na coexistência entre ambos, mas também a presença de distintas concepções e interpretações sobre o lugar e o significado da solidariedade no terreno dos interesses".

O ponto central do pensamento do autor desenvolvido neste livro é que não se pode despolitizar a CID, separando e preterindo a solidariedade em relação ao interesse, ou vice-versa. Ao ignorar que se trata de mais uma arena de políticas públicas, de que participam uma diversidade de atores (com interesses), perde-se a noção de que é preciso cobrar transparência e de que se pode contar com a prestação de contas do uso de recursos públicos, garantindo, assim, espaço de participação social nas políticas externas e de cooperação" . Sobre essa tese, diz o autor "Ao definir a CID como campo político, estou menos preocupado com a distinção clara das fronteiras entre interesses comerciais, financeiros e humanitários, e mais estimulado a analisar como, na prática dos projetos implementados e na construção de uma retórica diplomática oficial, tais interesses relacionam-se uns aos outros, podendo apoiar-se mutuamente ou, em muitos casos contradizer-se" (p. 24).

O livro discute as principais questões da CID à luz de alguns estudos de caso e, ao final, a experiência do Brasil. O conteúdo está organizado em torno dos seguintes temas: no primeiro capítulo, o histórico e a institucionalização da CID, bem como as relações de poder existentes; no segundo capítulo, a contribuição das organizações

\footnotetext{
1 Para este tema, sugerimos Pomeroy e Waisbich (2019) na Revista Brasileira de Políticas Públicas e Internacionais - RPPI 4 (1), p. 105-130 sobre os "Formatos e determinantes da participação social em agendas da Política Externa Brasileira", e Waisbich (2020) na Revista Brasileira de Política Internacional RBPI 63 (2), sobre "Negociating accountability in South-South Cooperation: the case of Brazil".
} 
multilaterais, suas normas, práticas e ideologias vigentes, especialmente os casos do Grupo Banco Mundial, das agências/programas/fundos das Nações Unidas e da União Europeia; no terceiro capítulo, a relação entre Estado, política externa e políticas de cooperação internacional conduzidas pelas agências bilaterais, como os casos analisados da USAID/Estados Unidos no âmbito da Cooperação Norte-Sul, e da TIKA/Turquia e da AMEXCID/México no âmbito da Cooperação Sul-Sul; no quarto e último capítulo, o Brasil é apresentado a partir da pergunta provocativa "O Sul é nosso Norte?", explicitando as tensões público-privadas presentes na construção de uma política pública de cooperação, por meio dos estudos de casos da cooperação em educação e no Haiti. Cada capítulo finaliza com algumas questões para debate, apresentadas ao final desta resenha, e possui suas referências bibliográficas, o que é muito útil para o uso didático do livro.

As duas noções principais da CID, a saber: a cooperação internacional e o desenvolvimento, são preponderantes para o atual sistema econômico capitalista. Conforme Milani, o atual sistema se expressa tanto nas relações coloniais quanto no atual liberalismo multilateral das relações internacionais ${ }^{2}$. Elas também estão associadas a três dimensões: econômica, social-moral e política e dizem respeito, respectivamente, ao ideal de progresso econômico, de solidariedade social e à necessidade de construção de amplos consensos políticos entre as nações. Portanto, é preciso considerar que para compreender a CID é preciso um conhecimento interdisciplinar e abordagens complexas/sistêmicas ${ }^{3}$.

No presente século XXI há um cenário muito mais complexo do que aquele de meados do século XX, quando a Guerra Fria iniciou a conformação de uma 'arquitetura da ajuda'. "Esse processo evoluiu à medida que o modelo de Estado nacional expandiuse da Europa para o mundo e que o sistema internacional se tornou mais complexo, passando a abarcar novos Estados (em função dos processos de descolonização) e atores não-estatais, a exemplo das ONG e das empresas transnacionais - que passaram, nos albores do século XXI, a desempenhar papel de legitimação enquanto mediadores intelectuais, parceiros políticos e cofinanciadores de projetos da CID." Com isso, além dos clássicos países 'doadores/prestadores' e 'beneficiários/recipiendários' ${ }^{4} \mathrm{da} C \mathrm{CID}, \mathrm{o}$ autor ressalta os atores mediadores, que configuram uma verdadeira 'indústria da ajuda', convergente com a conhecida crítica formulada por Arturo Escobar sobre a profissionalização e institucionalização do desenvolvimento ${ }^{5}$.

\footnotetext{
${ }^{2}$ Explica o autor que a CID pode ser considerada um fator integrante e legitimador do capitalismo e da modernização (variável independente), porém, ao mesmo tempo, decorre da expansão e integração dos mercados, do plano local (e nacional) ao internacional e global (variável dependente).

${ }^{3}$ Mais especificamente sobre a Cooperação Sul-Sul, Caixeta (2015) em Conjuntura Austral 32 (6) p. 4-18 sugere que é preciso novos referenciais teóricos-metodológicos para que se possa compreender e, também, apoiar a realização da CSS, a partir do campo das Relações Internacionais e das Ciências Sociais. ${ }^{4}$ Não se pode perder de vista a contestação por parte de alguns países emergentes, como o Brasil, que se recusam a ser caracterizados como 'países doadores', tentando garantir coerência com os princípios da Cooperação Sul-Sul e cobrar responsabilidades diferentes em relação aos países do Norte na CID; a CSS deve ser vista como modalidade complementar à CID, como defendido pelo Sul global, incluindo as organizações da sociedade civil na última Conferência da CSS (PABA+40) em março de 2019. Disponível em: https://www.realityofaid.org/wp-content/uploads/2019/03/Statement FirstDraft Southern-CSOAlliance-on-South-South-Cooperation.pdf
}

${ }^{5} \mathrm{Na}$ obra "A invenção do terceiro mundo", Escobar (2007) explica que o discurso do desenvolvimento cria
conceitos, teorias e práticas que serão controlados pelos atores com conhecimento e competência: as 
Outro tema desenvolvido pelo autor no primeiro capítulo que merece destaque é a sistematização dos principais eventos que fazem parte da institucionalização da CID. Cada categoria dos fatos históricos corresponde a graus diferenciados de relevância política no estágio inicial de institucionalização, que vai de 1942 com a criação informal da ONU até 1971 com o lançamento do Enfoque do Marco Lógico (logframe-logical framework), importante ferramenta de avaliação de projetos usada até o presente. A primeira categoria dos eventos históricos é a da política externa e diplomacia dos Estados, que diz respeito aos interesses enquanto doadores e as reações dos países em desenvolvimento; a segunda, às instituições políticas, ou seja, os acordos assinados, mecanismos desenvolvidos e a maneira pela qual os Estados se organizam, individual ou coletivamente, a fim de canalizar os financiamentos aprovados - merece destaque a década de 1960 quando os países doadores criam suas próprias agências e conformaram a OCDE; a terceira categoria diz respeito à emergência dos ideários, um conjunto de visões de mundo, teorias, ideologias e princípios que justificam para a opinião pública os recursos financeiros direcionados à CID - inclui-se aí a contestação a alguns fundamentos filosóficos e políticos da ajuda internacional na Conferência de Bandung de 1955 que suscitou a Cooperação Sul-Sul (CSS); a quarta e última categoria de eventos é a dos recursos financeiros e técnicos mobilizados, com destaque para o Plano Marshall, o mais importante programa no processo de institucionalização da CID, e o Enfoque do Marco Lógico mencionado.

Ao se perguntar se a CID é um regime, subsistema internacional ou um campo político, Milani propõe uma tabela organizando as principais visões sobre a CID em dois níveis - o micro, dos agentes e o macro, estrutural - e em três tipos de perspectivas teóricas: as visões otimistas, provenientes do liberalismo, as céticas que argumentam a partir do realismo, e as críticas, que partem do marxismo e da teoria crítica. Também para fins analítico-teóricos, no final do livro o autor propõe três abordagens teóricas ou dimensões associadas às justificativas solidárias apresentadas pelos distintos atores, a saber: a econômica, a social-moral e a política, mobilizando para tal, respectivamente, os debates sobre o desenvolvimento nacional e a eficácia do desenvolvimento; a ética global, a sociedade internacional (com atenção para a Escola Francesa das RRII); e aqueles sobre a política internacional e a economia política internacional (EPI).

O papel desempenhado pelas organizações multilaterais neste cenário é tema do segundo capítulo. $\mathrm{O}$ autor explica que elas possuem influência decisiva na formulação, planejamento e implementação das políticas públicas, na escolha de ferramentas de gestão orientadas para a obtenção de resultados e, também, no estabelecimento de parcerias público-privadas. No sentido inverso, entretanto, as organizações têm sido palco para as propostas de mudança da ordem mundial pelo Sul global, conforme Milhorance e SouleKohndou (2017) demonstraram num estudo sobre a CSS e as mudanças ocorridas neste século XXI em organizações como o PNUD, a FAO e o PMA ao incorporarem práticas, atores (da sociedade civil inclusive) e narrativas em suas atividades, além de adotarem a CSS como estratégia de implementação de seus mandatos.

A dicotomia entre a cooperação multilateral e a bilateral também permite evidenciar o perfil de determinados países na CID quanto a seus interesses e forma de

organizações internacionais, alguns governos "bem sucedidos" e os especialistas em analisar, avaliar e desenhar programas nas instituições; assim, os programas se traduzem em instrumentos de poder e controle. 
solidarizar com o desenvolvimento. Por exemplo, o autor mostra como os paísesmembros do CAD/OCDE tendem a investir mais na cooperação bilateral do que multilateral, sendo que Suécia, Luxemburgo, Noruega, Dinamarca, Países Baixos, Finlândia são os campeões da cooperação multilateral, com parcelas relativas bastante mais elevadas em comparação com países como Grécia, Portugal, Estados Unidos, Itália e Coreia do Sul, que se encontram no outro extremo desse continnum entre cooperação multilateral e bilateral. Em relação ao Sul global, países como Índia e China investem mais na cooperação bilateral, inclusive via investimentos e comércio exterior, e países como o Brasil, África do Sul e o México utilizam as agências multilaterais para canalizar sua oferta de cooperação, sobretudo a cooperação técnica em pautas setoriais coincidentes com as políticas públicas domésticas mais exitosas, como é o caso da agricultura familiar no caso do Brasil, que colocou José Graziano da Silva na direção-geral da FAO ${ }^{6}$.

No entanto, um dos desafios desse campo tem sido demonstrar os resultados da CID diante dos débeis nexos de causalidade. $\mathrm{O}$ autor comenta a falta de evidências e de uma visão clara entre as transformações sociais produzidas no contexto do desenvolvimento (efeitos) e os projetos e programas de cooperação fornecida (causa). No âmbito da Cooperação Sul-Sul, uma proposta para a adoção de indicadores para o monitoramento e avaliação dos projetos foi, entretanto, apresentada pelo BPC e ASUL, com apoio da Agência Brasileira de Cooperação (ABC) em 2017 . A questão da efetividade da CID é tão central que deu nome ao encontro de alto nível entre os membros do CAD/OCDE - o Fórum sobre a Efetividade da Ajuda - e à iniciativa das organizações da sociedade civil (OSC) envolvidas com a CID - a Aliança de OSC para a efetividade do desenvolvimento ${ }^{8}$.

Nesse sentido, compreender o papel desempenhado pelas agências bilaterais de cooperação para o desenvolvimento, tanto nos países do Norte quanto do Sul global, oferece grandes desafios. Além de fazer convergir a cooperação e as agendas de política externa dos Estados, também articula políticas setoriais. Daí o interesse em desvendar os diferentes marcos interpretativos vigentes, que produzem diferentes resultados nas concepções de políticas de cooperação bilateral. Um quadro dos diferentes marcos, com as respectivas previsões e variáveis, é apresentado pelo autor como uma proposta analítica, indo da segurança, poder e influência até a obrigação e dever e os valores humanitários.

Talvez, uma das questões centrais do terceiro capítulo é o fato de que nesse momento é imperioso reconhecer que o Estado não é um ator monolítico. Não há um discurso oficial uníssono, ao contrário, a política externa como política pública implica em que a política de CID dos países é aberta aos conflitos de interesses. Então, torna-se fundamental discutir como se constroem as agendas no plano doméstico. Reafirma-se a

\footnotetext{
${ }^{6}$ Sugerimos a leitura do relatório "From Fome Zero to Zero Hunger: a global perspective" (FAO, 2019). Disponível em: http://www.fao.org/3/ca5524en/ca5524en.pdf

${ }^{7}$ Nessa proposta, busca-se integrar os princípios de política externa aplicados à CSS, os princípios e elementos orientadores da CSS, os elementos para o alcance de objetivos da CSS e os elementos que estabelecem os objetivos da CSS. A publicação está disponível em https://bricspolicycenter.org/publicacoes/caminhos-para-construcao-de-sistemas-e-processos-demonitoramento-e-avaliacao-da-cooperacao-sul-sul/

${ }^{8}$ Os oito Princípios de Istambul pactuado entre as OSC para a eficácia do desenvolvimento estão disponíveis em http://cooperacao-desenvolvimento.blogspot.com/2010/12/linhas-mestras-principiosde-istambul.html e mais informação sobre a AOED (Alianza de OSC para la Eficacia del Desarrollo) pode ser acessada em https://csopartnership.org/es/sobre-nosotros/
} 
noção de que as decisões sobre a concepção e implementação das políticas de CID, e também de CSS, são objeto de barganha entre os atores institucionais e não governamentais no plano doméstico. Contudo, de forma geral, entre os países em desenvolvimento há um déficit de institucionalização dessa agenda, o que resulta em dificuldades para a construção de convergências normativas e a avaliação conjunta das práticas cooperativas, além da transparência e prestação de contas.

Em termos de motivação no plano internacional, Milani afirma que a diferenciação entre CNS e CSS é fundamentalmente empírica. Isso porque é preciso reconhecer que a CSS, apesar de ser parte de um ativismo multilateral, em meio à crise do capitalismo, ainda se encontra em construção. Essa diferenciação, portanto, implica metodologicamente ir além das promessas e discursos dos países ofertantes, para avançar na compreensão sobre a realidade dos países quanto aos projetos em curso, aos impactos na perspectiva do 'outro' beneficiário. Daí a necessidade de uma pesquisa situada, ou seja, de realização de estudos de caso.

Assim, a experiência do Brasil é analisada, no quarto capítulo, tanto no nível sistêmico, que trata da relação com os demais países do Sul global e mesmo com a OCDE, quanto no nível do Estado, enfocando a relação da política externa com a CSS, na ABC. No primeiro nível, o "dilema da graduação", já discutido pelo autor, indica que a vontade política de graduar-se como Estado na CID, via CSS, coloca alguns dilemas, quais sejam: entre a contestação dos países centrais e o risco de não ser reconhecido como liderança regional pelos seus vizinhos latino-americanos, e entre usar as organizações multilaterais para mudar o status quo almejado (numa ordem internacional assimétrica e hierárquica) e o uso estratégico de parcerias bilaterais para os fins maiores da política externa. Além disso, a graduação requer que os tomadores de decisão construam justificativas legítimas para serem comunicadas aos cidadãos nacionais.

Neste contexto, pode-se entender o levantamento do orçamento público do governo federal investido na Cooperação Brasileira para o Desenvolvimento Internacional (COBRADI). Em busca do reconhecimento global, ele provocou maior interesse e envolvimento da sociedade civil brasileira nessa agenda ${ }^{9}$. Ao analisar os relatórios entre 2005 e 2013, Milani mostra como os gastos são crescentes e, embora o pico tenha sido em 2010, os montantes para os anos de 2011, 2012 e 2013 são mais altos do que aqueles prévios a 2010. Isso significa que, a despeito da crise que atravessou o Brasil no primeiro mandato de Dilma Rousseff ${ }^{10}$, os orçamentos destinados à CSS ainda eram muito expressivos ${ }^{11}$.

\footnotetext{
${ }^{9}$ Destacamos aqui a proposta alternativa à do IPEA intitulada "A procura da Cooperação Sul-Sul no Orçamento Público Brasileiro", uma iniciativa do Articulação Sul, uma ONG brasileira com apoio da Oxfam Brasil. O relatório está disponível em: https://www.oxfam.org.br/publicacao/a-procura-da-cooperacaosul-sul-no-orcamento-federal/

${ }^{10}$ Sabe-se que nos governos petistas, a ênfase nas relações Sul-Sul foi instrumental para um projeto mais ambicioso de protagonismo regional e global do país; envolveu agentes políticos internos e empresas brasileiras que disputaram mercados internacionais nos setores de construção civil, energia, aviação regional e agricultura. $\mathrm{O}$ segundo mandato de Dilma Rousseff, contudo, abandonou a diplomacia 'ativa e altiva' do chanceler Celso Amorim e reduziu a projeção política das atividades da ABC no campo da CSS, explica o autor.

${ }^{11}$ Os quatro relatórios COBRADI, de iniciativa do IPEA em parceria com a $A B C$, publicados até o presente momento (2005-2009; 2010; 2011-2013 e 2014-2016) estão disponíveis em: https://www.ipea.gov.br/portal/index.php?option=com content \&view=article\&id=32420\&ltemid=343
} 
A partir do estudo dos casos da cooperação em educação e com o Haiti, segundo o autor, algumas lições aprendidas pelo Brasil são: a necessidade de uma reforma do desenho institucional da política de CSS; de investir na capacidade institucional dos entes governamentais participantes da CID e CSS; de contar com um quadro regulatório adequado e financiamentos sustentáveis, e de desenvolver um mecanismo de avaliação das iniciativas; além disso, é preciso realizar um debate normativo com a participação da sociedade civil e considerar a percepção dos países parceiro-beneficiários das iniciativas.

Como agendas para pesquisas futuras, Milani aponta uma série de questões para debates que podem ser usadas tanto por pesquisadores em busca de maior compreensão do campo quanto pelos docentes em sua missão de estimular a reflexão e o interesse dos estudantes por este tema. Entre elas, destacamos: a relação entre a ética movida pelo interesse coletivo e as práticas de interesse mútuo (o 'solidarismo internacional') e as relações entre os Estados movida pelo poder/política e menos sobre a moral; as bases materiais (recursos produtivos, tecnológicos, financeiros) e imateriais (recursos normativos, ideológicos e cosmogônicos) que guiam o relacionamento entre os atores da CID; os 'subdesenvolvidos' como categoria simplificadora, porquanto as populações ajudadas não são os latino-americanos, quéchuas e mongóis que foram colonizados e são até hoje explorados, mas os povos subdesenvolvidos, que provoca uma 'piedade distanciada'; o predomínio do $\mathrm{CAD} / \mathrm{OCDE}$, uma organização seletiva e sem vocação universal, na produção de dados, análises, critérios e normas no campo da CID, e mesmo da CSS, sobre o Fórum de Cooperação para o Desenvolvimento da ONU, que não é efetivo na missão de coordenar a CID; a efetividade da cooperação requer levar em consideração a capacidade de absorção das sociedades nacionais, ir além da métrica do nexo ajuda-crescimento; a disputa da CSS entre a pluralidade de países e a fraca institucionalização que, no âmbito multilateral, significa pouca sistematização e transparência dos dados (volumes, prioridades, setores).

Na conclusão do livro, damos voz ao autor que defende a realização de pesquisas empíricas. Isso é, certamente, o que mais se anseia no campo da Cooperação Sul-Sul ao se questionar sobre a existência, ou não, de uma cooperação horizontal, solidária e eficiente:

Desse modo, a análise da cooperação como agenda da política externa dos Estados (superpotências, grandes potências, potências médias) nos permite enxergar a permanência de uma faceta das relações Norte-Sul na geopolítica atual, mas também os riscos de emergência de novas formas regionais e globais de dominação e dependência Sul-Sul. Portanto, é necessário seguir investindo em pesquisas empíricas, que dialoguem com marcos teóricos críticos, e nomeadamente, em pesquisas comparativas sobre as diferentes estratégias de CSS, sem negligenciar, na análise, a dialética existente entre cooperação pública (governamental), o papel das organizações não governamentais, os financiamentos públicos concedidos a corporações privadas em processo de internacionalização e os investimentos por ela realizados (Milani, 2018: 311).

Por Marina Bolfarine Caixeta. Doutoranda da Universidade de Brasília (UnB) Departamento de Estudos Latino-americanos. Bolsista do CNPq. Correo electrónico: marinabolfarinecaixeta@gmail.com. ORCID: https://orcid.org/0000-0003-0462-506X 